\title{
Geometrically Nonlinear Transient Response of Laminated Plates with Nonlinear Elastic Restraints
}

\author{
Shaochong Yang ${ }^{1,2}$ and Qingsheng Yang ${ }^{1}$ \\ ${ }^{1}$ Department of Engineering Mechanics, Beijing University of Technology, Beijing 100124, China \\ ${ }^{2}$ College of Civil Engineering and Architecture, Hebei University, Baoding 071002, China \\ Correspondence should be addressed to Qingsheng Yang; qsyang@bjut.edu.cn
}

Received 27 October 2016; Revised 21 December 2016; Accepted 4 January 2017; Published 19 January 2017

Academic Editor: Yuri S. Karinski

Copyright (C) 2017 Shaochong Yang and Qingsheng Yang. This is an open access article distributed under the Creative Commons Attribution License, which permits unrestricted use, distribution, and reproduction in any medium, provided the original work is properly cited.

\begin{abstract}
To investigate the dynamic behavior of laminated plates with nonlinear elastic restraints, a varied constraint force model and a systematic numerical procedure are presented in this work. Several kinds of typical relationships of force-displacement for spring are established to simulate the nonlinear elastic restraints. In addition, considering the restraining moments of flexible pads, the pads are modeled by translational and rotational springs. The displacement- dependent constraint forces are added to the righthand side of equations of motion and treated as additional applied loads. These loads can be explicitly defined, via an independent set of nonlinear load functions. The time histories of transverse displacements at typical points of the laminated plate are obtained through the transient analysis. Numerical examples show that the present method can effectively treat the geometrically nonlinear transient response of plates with nonlinear elastic restraints.
\end{abstract}

\section{Introduction}

In recent years, laminated plates have been extensively used as structural members in aviation, aerospace, civil, automotive, marine, and other industries, due to their excellent fatigue behavior, superior impact resistance, light weight, and high strength characteristics. These laminated plates are usually fixed by nonlinear restraints, which include gap and spring in series, bilinear spring, softening and hardening system, flexible pads, and in-plane friction. The dynamical behaviors of plates with nonlinear restraints are definitely different from those with simple boundary conditions. It is well known that classical rectangular plate edge conditions are clamped and simply supported, which are easy to simulate with fixed displacement constraint in finite element method. In practical applications, the nonlinear restraints cannot be modeled by classical boundary conditions. Therefore, the nonlinear transient response of laminated plates with nonlinear restraints, which will be addressed in this work, is an important issue in the engineering.

The thin plates easily undergo large-amplitude vibrations and large deformations when subjected to severe dynamic loading. In recent years, there have been many studies on nonlinear vibration analysis of the components under dynamic loads. Kurtaran [1-3] conducted geometrically nonlinear transient analysis of laminated composite structures with generalized differential quadrature method. Susler et al. [4] investigated the geometrically nonlinear dynamic behavior of tapered laminated composite plates with simply supported and subjected to air blast loading. Moreover, there have been several literatures on the vibration analysis of plates and shells with various shapes and boundary conditions [57]. For instance, Nanda and Bandyopadhyay [8] used the finite element method to investigate the nonlinear transient response of composite shells with/without cutouts and initial geometric imperfection. Amabili $[9,10]$ utilized Von Karman nonlinear strain-displacement relations to investigate the large-amplitude vibrations of rectangular plates with different boundary conditions.

There are numerous methods to analyze the nonlinear dynamic response of plates or rod, such as total Lagrange approach [11], semianalytical finite strip method [12], Newton's method [13], and finite element iteration method [14]. As 
illustrated in [15], the classical Von Karman theory, the firstorder shear deformation theory, and the higher-order shear deformation theory are compared for studying the nonlinear forced vibrations of isotropic and laminate composite rectangular plates. Among the different nonlinear analysis methods, the finite element method has been widely used in solving nonlinear problems because of its easy implementation with any boundary condition and arbitrary geometry.

In addition, there have been a lot of studies dealing with dynamic response and vibration of beams and plates with nonlinear restraints when subjected to various dynamic loads [16-20]. Sedighi et al. [21, 22] used He's parameter expanding method to obtain the analytical solution of dynamic behavior of the cantilever beam with a nonlinear boundary condition. Li et al. [23-25] developed an analytical method for the vibration analysis of rectangular plates with elastically restrained edges and demonstrated the accuracy and reliability of the presented method through some examples. Stojanović [26] investigated geometrically nonlinear vibrations of a beam on a nonlinear elastic foundation with variable discontinuity. Yamaguchi et al. [27] assumed that the restoring force of the support spring has cubic nonlinearity and linear hysteresis damping. Duc et al. [28] investigated the nonlinear dynamic response and vibration of the imperfect laminated nanocomposite panel resting on elastic foundation and subjected to hydrodynamic loads. Shooshtari and Razavi [29] studied the nonlinear and linear free vibration of symmetrically laminated magnetoelectroelastic doubly curved thin shell on an elastic foundation. Moreover, there are many methods to study the free vibration of the plates with elastic edge restraints, such as an accurate variational formulation [30], a general Ritz formulation [31], the superposition method [32], and the differential quadrature method [33]. Based on the existing literatures, only a few reports have focused on the geometric nonlinearity and the nonlinearity of boundary conditions in the vibrating systems at the same time. Therefore, it is very important to predict accurately the transient response of these structures under dynamic loading.

In view of the fact that the dynamical behaviors of plates with nonlinear elastic restraints are very different from those with simple boundary conditions, in this work, the attention is paid to the treatment of nonlinear elastic restraints. The large deflection of the plates and the nonlinearity of constraint conditions in the transient analysis are considered at the same time. Since the boundary conditions of elastic supported plate are not rigidly clamped and are assumed to allow small deflections and slopes, in this paper, the flexible pads of the plate are modeled by translational and rotational springs. A varied constraint force model and a systematic numerical procedure are presented to solve the geometrically nonlinear transient response of laminated plates with nonlinear elastic restraints. The varied constraint forces of the nonlinear restraints are treated as additional applied loads. These loads are explicitly defined, via an independent set of nonlinear load functions in the computational platform of MSC/Nastran, which satisfy the various constraint conditions for specific cases. The nonlinear equations are solved by using the load increments scheme in conjunction with Newton-Raphson iteration. Finally, using this computational

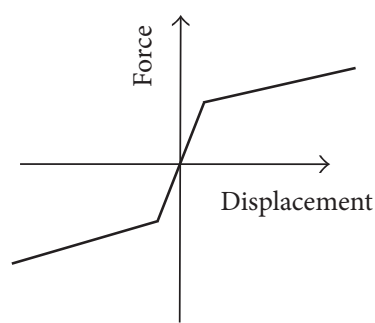

(a)

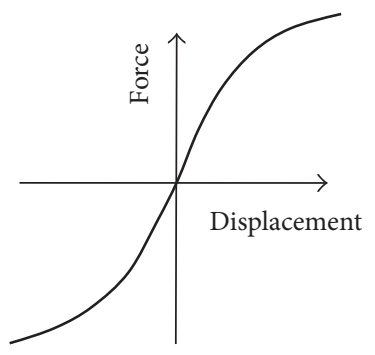

(c)

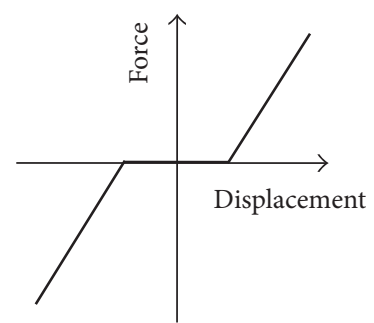

(b)

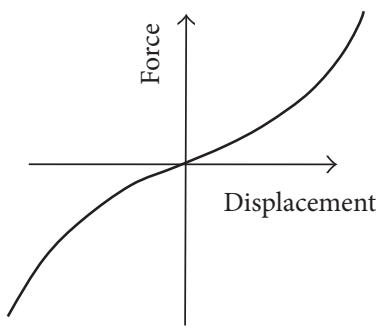

(d)
FIGURE 1: Force-displacement relation of nonlinear elastic restraints: (a) bilinear spring; (b) gap and spring in series; (c) softening system; (d) hardening system.

approach, three different examples with different nonlinear restraints are implemented, respectively.

\section{Mathematical Models of Nonlinear Elastic Restraints}

The nonlinear elastic restraints possess nonlinear forcedeformation relationships, yet they are elastic since they load and unload along the same force-deflection curve. The nonlinear restoring forces of the restraints undergo changes in terms of dynamic varied displacements. Typical forcedisplacement curves of the nonlinear elastic restraints are shown in Figure 1. These types of restraints are common in many mechanical and structural systems including the systems connected with nonlinear springs (bilinear spring, gap and spring in series, softening, and hardening [34]) and plates supported by flexible strip-type pads.

The constitutive equation of the hardening system $[27,35$, 36 is usually expressed as

$$
F=k u+\alpha k u^{3},
$$

where $F$ denotes constrained force, $k$ denote stiffness constants, $u$ denotes displacement, and $\alpha$ is a small parameter. The constrained force undergoes variations in terms of variable displacement.

\section{Dynamics Model of Laminated Plate with Flexible Pads}

The plate is supported by flexible strip-type pads of crosssectional dimensions $b_{e} \times h_{e}$ and Young's modulus $E_{e}$ at the couple of short edges, as shown in Figure 2(a). For the flexible 


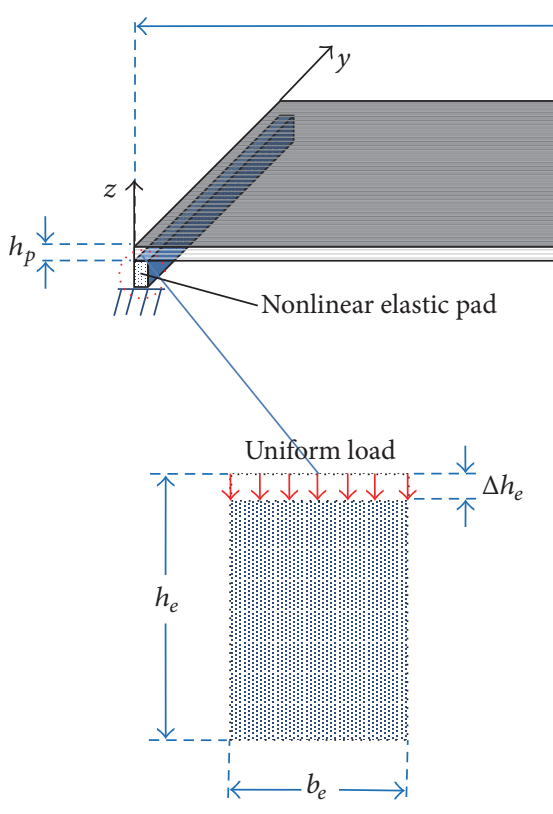

(b)

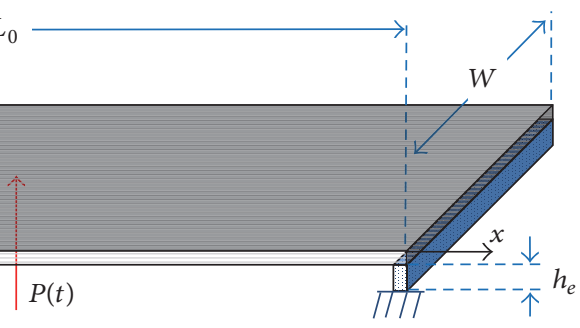

(a)

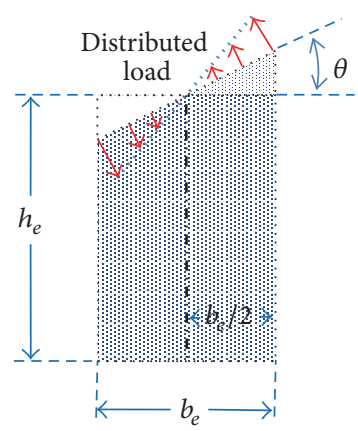

(c)

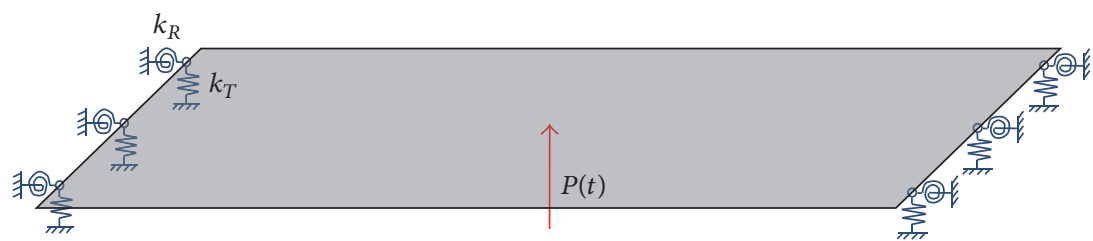

(d)

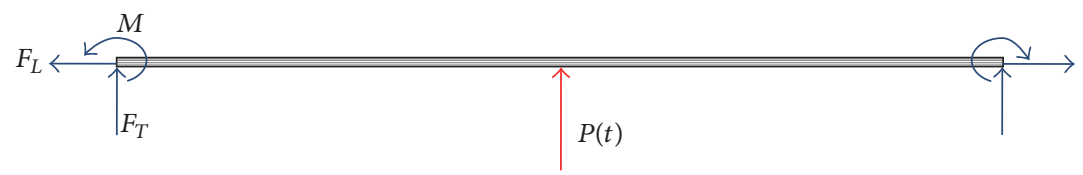

(e)

FIGURE 2: Mathematical model of plate supported by flexible strip-type pads at both short edges: (a) diagram of the system; (b) vertical deformation and force diagram; (c) bending deformation and force diagram; (d) flexible supports modeled by translational and rotational springs; (e) free body diagram.

supports considered in this study, it is further assumed that the dimensions $b_{e}$ of the pads are much smaller than the plate dimensions $L_{0}$; hence, the edge flexible supports of the plate can be modeled by translational and rotational springs as shown in Figure 2(d). The constraint reactions $F$ and $M$ undergo variations in terms of variable displacements $u$ and $\theta$, respectively, as shown in Figure 2(e).

The equivalent translational and rotational spring constants of the flexible strip-type pad as an edge support are approximately determined by the mechanics of materials approach [37]. For the derivation of the translational spring constant, it is assumed that the load is distributed uniformly on the top surface of the flexible pad. The top surface remains plane and horizontal after deformation as shown in Figure 2(b). Assuming the flexible pad undergoes linear elastic deformation, the translational spring constant per unit length can be written as

$$
k_{T}=\frac{E_{e} b_{e}}{h_{e}} .
$$

To determine the rotational spring constant, it is assumed that the deformation is distributed linearly across the width of the support where the top surface of the pad remains plane after rotation $\theta$ as shown in Figure 2(c). Hence, the rotational spring constant per unit length is given as

$$
k_{R}=\frac{E_{e} b_{e}^{3}}{12 h_{e}} .
$$




\section{Equation of Motion with an Additional Load Vector}

In order to solve nonlinear transient response of the plate supported by nonlinear elastic restraints, the nonlinear restoring forces of restraints are treated as additional applied loads $[34,38,39]$. The nonlinear relation of the force component and the displacement can be explicitly defined. The dynamics equation of the structure can be written as

$$
\begin{aligned}
& {[M]\{\ddot{u}(t)\}+[C]\{\dot{u}(t)\}+[K]\{u(t)\}} \\
& \quad=\{p(t)\}+\{N(u)\},
\end{aligned}
$$

where $[M],[C]$, and $[K]$ denote the system mass, damping, and stiffness matrices, respectively. The vectors $\{p(t)\}$ and $\{u(t)\}$ denote applied nodal loads and system displacements, respectively, being functions of time. The vector $\{N\}$ denotes the nonlinear forces supplied by nonlinear elastic restraints, depending on the displacements $\{u\}$, which can be treated as additional applied loads. The nonlinear forces are evaluated at the end of one time step for use in the successive time step. The equations of motion therefore become the following:

$$
\begin{gathered}
{[M]\{\ddot{u}(t)\}+[C]\{\dot{u}(t)\}+[K]\{u(t)\}} \\
=\{p(t)\}+\{N(t-\Delta t)\} .
\end{gathered}
$$

Note that the nonlinear force lags the true solution by a time step, which may require using small integration time steps. These loads can be explicitly defined, via an independent set of nonlinear load functions that satisfy the various constraint conditions for specific cases.

\section{Computational Procedure: Load Increments, Iterations, and Stiffness Update}

The computational procedure involves incremental and iterative processes ranging from local subincrements to global solution processes. In the loading history, the total of load applied during a step can be subdivided into small parts to ensure the solution to be prone to converge. These subdivisions within a subcase are termed as load increments for each time step. In the incremental solution process, the unbalanced forces produced during a load increment for each time step are reintroduced internally into the solution until the solution has converged. The process of redistributing the unbalanced force within a load increment for each time step is known as an iteration. As illustrated in Figure 3, a complete description of the numerical procedure used to solve the nonlinear problem is given for reference.

It is important to note that the total load is applied gradually in the computational steps (or increments) for each load step; the solution convergence is achieved after one or more iterations. Each iteration involves an assembly and solution of the stiffness matrix. At the end of each iteration, a check is made to see if the solution has converged. If the convergence check fails, the iteration is repeated with the new information. This process repeats until convergence is achieved. Subsequently, the next increment of load is applied [40]. In

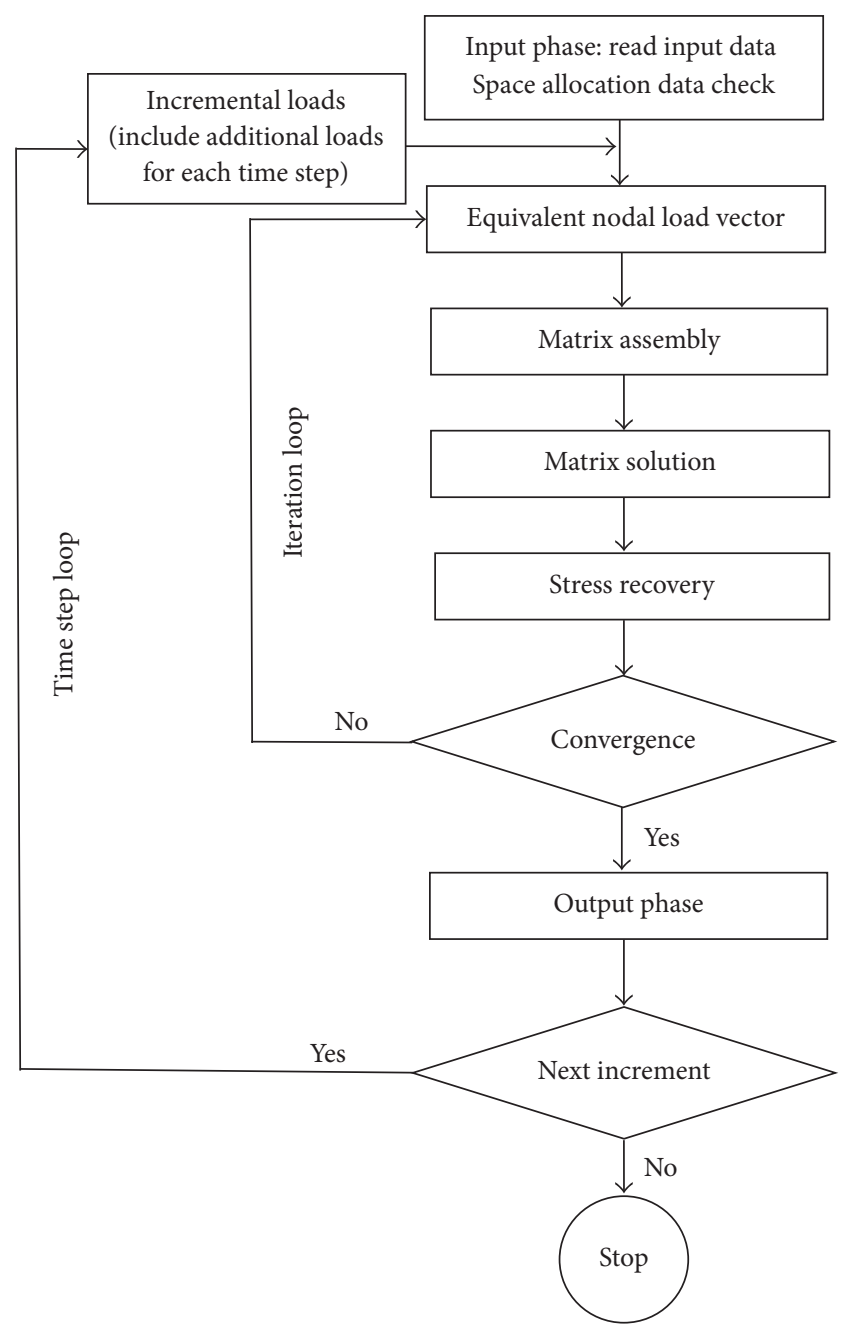

FIGURE 3: Flow diagram of nonlinear solution with additional loads.

addition, the solution procedure is more complex for the structures system with nonlinear elastic supports. The variable restraining forces as additional loads are added to equations of motion. The restraining forces in terms of dynamic displacements undergo changes at each time step loop. The load increments for each time step are applied until the full load of the model is prescribed.

For geometrically nonlinear problems, the system of equations must be solved many times to follow the behavior of the deformed structure. The nonlinear variation may arisen from the shape or loading changes. The stiffness of the structures changes and must be considered by regenerating the stiffness matrix in a nonlinear analysis. The element stiffness is

$$
[K]^{e}=\int_{V}[B]^{T}[D][B] d V,
$$

where $B$ and $D$ refer to the strain matrix and the tangential stiffness matrix (elasticity matrix), respectively.

Notice that this expression represents element stiffness due to the material stiffness without geometric nonlinear effects. Additional stiffness $K^{d}$ due to initial stresses should 


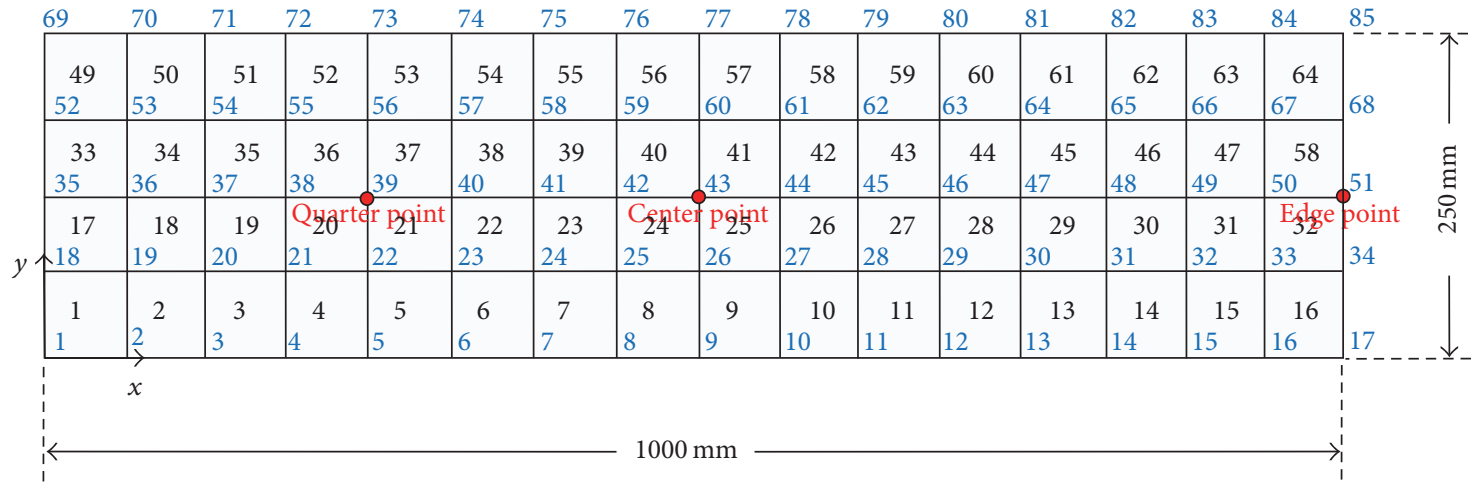

Figure 4: Nodes and elements in finite model of laminate plate.

be included for an incremental process because the initial stresses exist from the second increment.

The tangential stiffness consists of the geometric stiffness in addition to the material stiffness, that is,

$$
\left[K_{T}\right]=\frac{\partial}{\partial u} \int_{V}[B]^{T}\{\sigma\} d V=\left[K^{m}+K^{d}\right]
$$

where $K^{m}$ and $K^{d}$ refer to the material and the differential stiffness, respectively. The material stiffness is given in (6) with a material tangential matrix for $[D]$.

The differential stiffness, which is caused by the initial stress, is defined as follows:

$$
\left[K^{d}\right]=\int_{V}\left[\frac{\partial B_{N}}{\partial u}\right]^{T}\{\sigma\} d V=\int_{V}[G]^{T}[\varphi][G] d V,
$$

where $B_{N}$ represents the second-order effects in the straindisplacement relations, $[G]$ consists of derivatives of shape functions, and $[\varphi]$ is a function of stresses.

\section{Numerical Examples}

In this section, we present three different examples that implement the above computational approach. In all cases, the laminated plates are supported by nonlinear elastic restraints. We consider a laminated plate with $1000 \times 250 \mathrm{~mm}$ as shown in Figure 4. The plate is $4 \mathrm{~mm}$ thick and is a laminate made up of 16 plies with equal thickness. The plies have two orientations, 0 and 90 degrees, that is, parallel to the plate edges. The laminate is uniform. Stacking sequence of symmetric composite layers is $\left[90^{\circ} / 0^{\circ} / 90^{\circ} / 0^{\circ} / 90^{\circ} / 0^{\circ} / 90^{\circ} / 0^{\circ}\right]_{\mathrm{s}}$. The material properties of the lamina are elastic modulus: $E_{11}=181000 \mathrm{MPa}, E_{22}=10300 \mathrm{MPa}$; shear modulus: $G_{12}=$ $G_{13}=7170 \mathrm{MPa}, G_{23}=5000 \mathrm{MPa}$; Poisson ratio: $\mu_{12}=0.28$; density: $\rho=1.6 \times 10^{-9}$ tonne $/ \mathrm{mm}^{3}$. The plate is meshed by 85 nodes and 64 Shell Elements (CQUAD4).

Example 1 (simply supported plate with a gap and spring in series restrained motion). In this example, the plate is simply supported at a couple of short edges and subjected to a single cycle of a sinusoidal load which can be expressed by $P(t)=A \sin (\omega t)$ at the quarter span (Node 39) as illustrated

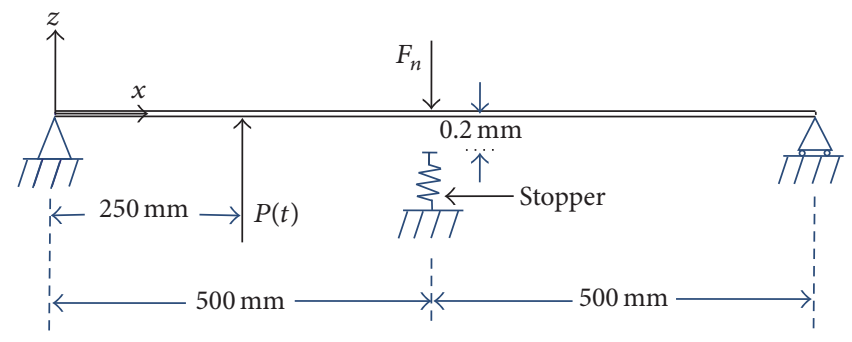

(a)

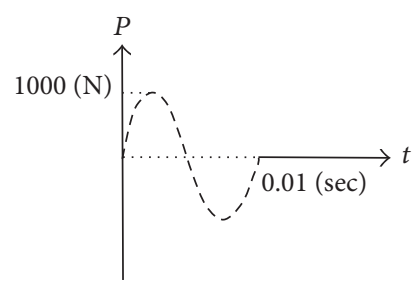

(b)

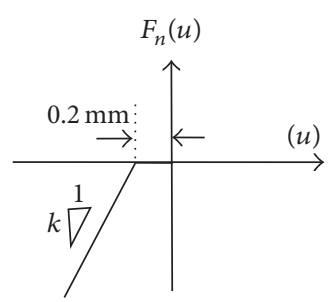

(c)
FIGURE 5: Simply supported plate at a couple of short edges with a gap and spring in series restrained motion: (a) front view; (b) forcing function; (c) gap and spring in series.

in Figure 5. The magnitude of load is $1000 \mathrm{~N}$, and the time duration is in a range from 0 to $0.01 \mathrm{~s}$. A stopper (snubber) is present underneath the center of the plate with a clearance of $0.2 \mathrm{~mm}$. This gap is simulated by a displacement dependent force which is active only when the plate is in contact with the snubber. When the plate is in contact with the snubber, $F_{n}(u)=k u$, where $k$ takes either $100 \mathrm{~N} / \mathrm{mm}$ or $1000 \mathrm{~N} / \mathrm{mm}$. For transient analysis, time step increment of $\Delta t=0.0001 \mathrm{~s}$ is used in analyzes. The displacements of typical grid points are computed through transient response analysis.

The displacement variation of center point is presented in Figure 6. It can be found in Figure 6, at the beginning, that the plate goes up and is not in contact with the restraint. It is seen that the transverse displacement-time curves, at the center position (Node 43) of the plate for different stiffness, overlap in the beginning time. As time goes on, the plate goes down and is in contact with the spring; the differences can be found between the curves for different stiffness. Moreover, when $k$ is 


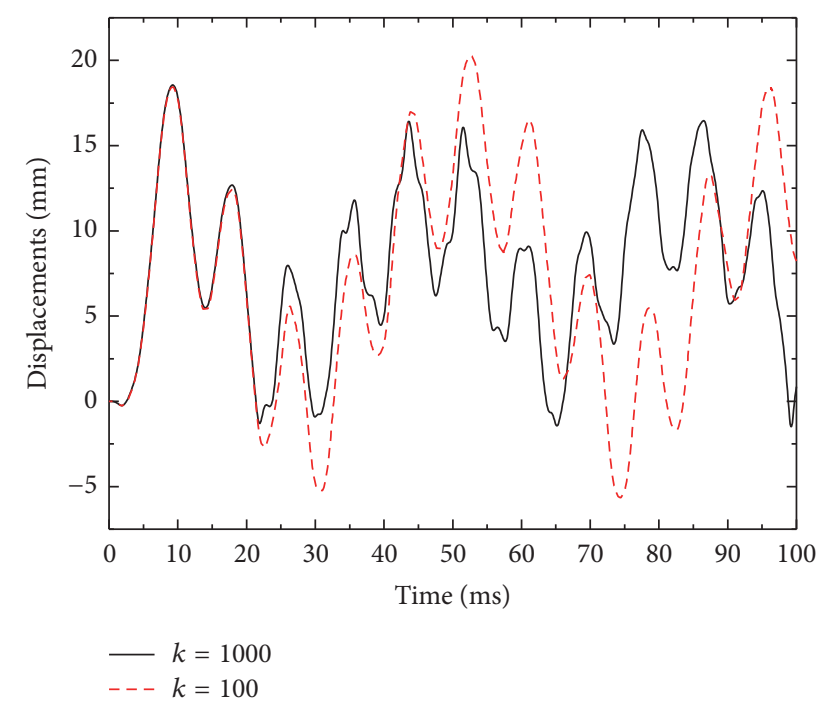

Figure 6: Transverse displacement history at the center point (Node 43) with different spring stiffness.

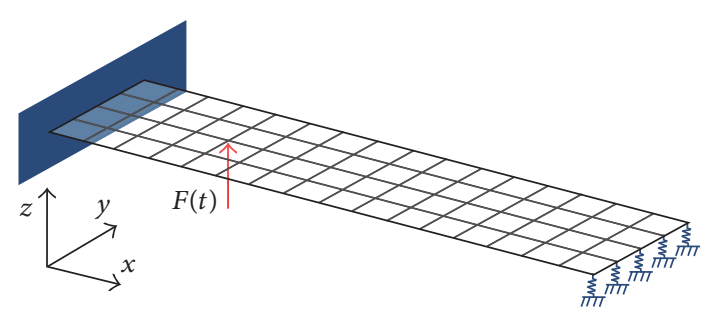

FIgURE 7: One end clamped and the other end with vertically hardening spring restraints.

$1000 \mathrm{~N} / \mathrm{mm}$, the plate bounces up immediately when the plate contacted with the restraint as shown in Figure 6. When $k$ is $100 \mathrm{~N} / \mathrm{mm}$, the plate moves down continually after contacting with the spring and then bounces up. From Figure 6, it is observed that, for the case of $k=100 \mathrm{~N} / \mathrm{mm}$, the curve is smooth, but for the case of $k=1000 \mathrm{~N} / \mathrm{mm}$, there are slight oscillations in the peak or trough of the curve. The downward amplitude for the case of $k=100 \mathrm{~N} / \mathrm{mm}$ is larger than the amplitude of the case of $k=1000 \mathrm{~N} / \mathrm{mm}$.

Example 2 (one end clamped and the other end with vertically hardening spring restraints). In the second example, sinusoidal forcing function, material properties, and stacking scheme for composite layer are the same as those presented in the previous example. As shown in Figure 7, the plate is considered to be clamped at one short edge and supported by nonlinear springs at the other short edge. As illustrated in Figure $1(\mathrm{~d})$, the spring force function can be expressed by $F(u)=$ $k u+\alpha k u^{3}$, where $k, u$, and $\alpha$ denote spring stiffness, displacement, and small constant, respectively. In this example, $k$ can be taken as 10,100 , and $+\infty \mathrm{N} / \mathrm{mm}$, respectively, where the case of $k=+\infty$ indicates simply supported constraint, $\alpha$ takes the value of 0.1 , and transient responses of the plate supported by nonlinear springs with different stiffness are analyzed.

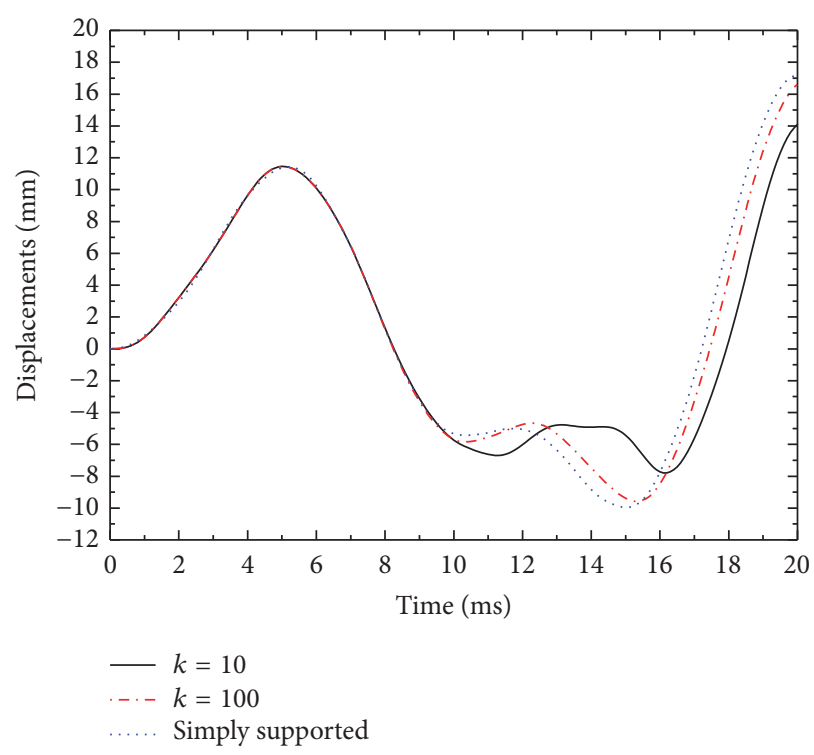

FIGURE 8: Transverse displacement history at the exciting point with different restraints.

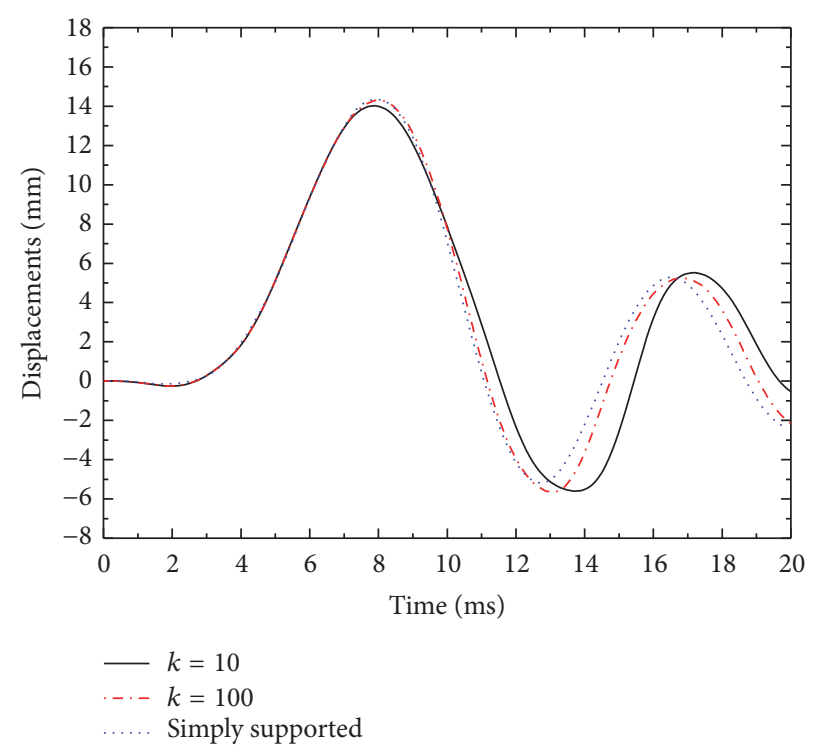

FIGURE 9: Transverse displacement history at the center point with different restraints.

The comparisons of the transient responses of typical points for different spring stiffness are made in Figures 8, 9, and 10, respectively. It is observed that the displacements are almost identical for different stiffness at the beginning force vibration period.

And then the difference emerges as the time goes on. It is seen from Figure 8 that the response is very timely at the exciting point of the plate. However, the response is hysteretic at the center and edge point of the plate as observed from Figures 9 and 10. The vibration amplitude and restraint stiffness present an inversely proportional relationship at the restraint point, but this relationship is not obvious at the center and exciting points. 


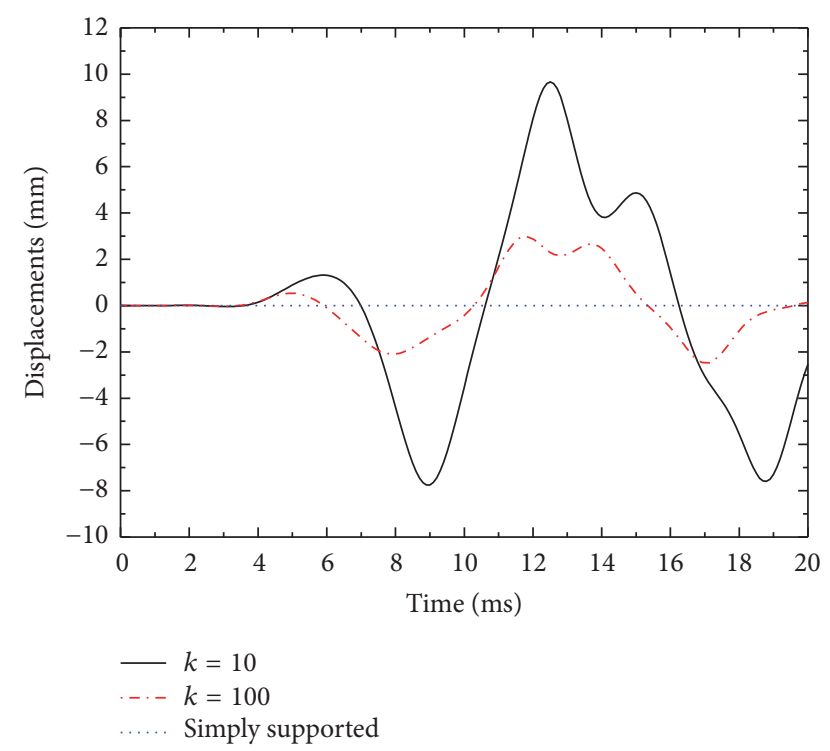

FIGURE 10: Transverse displacement history at the edge point with different restraints.

Example 3 (plate supported by flexible strip-type pads at both short edges). In the third example, the plate is supported by flexible strip-type pads at the couple of short edges and subjected to a dynamic force which is the same as those given in the previous example at the center span (Node 43) in Figure 2. In order to verify the validity of the present method, the nonlinear transient response of the laminated plates with simply supports at both short edges is analyzed too, where the simply supported case is indicated by $k_{T}=+\infty, k_{R}=0$. In this example, the cases of with/without rotational spring restraint are analyzed, respectively.

Transient analyzed results of center points are plotted in Figure 11. In this example, $E_{e}$ is $2.028 \mathrm{MPa}$, the cross-sectional dimensions of strip-type pads are $25 \times 10 \mathrm{~mm}$, based on (2)-(3), the translational spring constant per unit length is $5 \mathrm{~N} / \mathrm{mm}^{2}$, and the rotational spring constant is $264 \mathrm{~N}$, respectively. From Figure 11, it is observed that the period of vibration with restraining moments is shorter than that without the restraining moments. Here, no obvious difference of the vibration amplitude can be found from the two cases.

\section{Conclusions}

In this paper, a varied constraint force model and a systematic numerical procedure are presented for the solution of geometrically nonlinear transient response of laminated plates with nonlinear restraints. Many kinds of nonlinear relationships of force-displacement for spring are established to simulate the actual engineering problem. And then the flexible pads of the plate are modeled by translational and rotational springs. The numerical examples examine the dynamics behavior of laminated plates with nonlinear restraints. The response results of plates with simply supports and nonlinear elastic restraints are compared to verify the validity of the

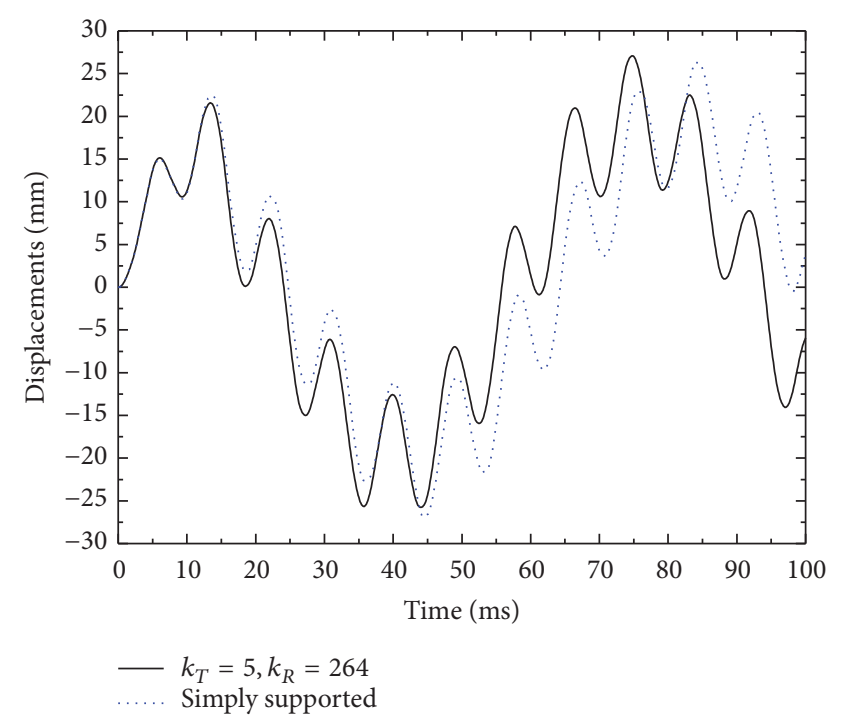

FIGURE 11: Transverse displacement history at the center point (Node 43) with/without rotation stiffness.

present method. The conclusions can be summarized as follows:

(1) To obtain the precise nonlinear dynamical response of the laminated plates, the influence of nonlinear restraints should be considered. The varied constraint force model and systematic numerical procedure can effectively treat the actual nonlinear elastic restraints of the system.

(2) The vibration amplitude and restraint stiffness present an inversely proportional relationship at the restraint point, but the difference of vibration amplitude for different restraint stiffness is not obvious at the center and exciting points, which means that the effect of the restraint stiffness on the vibration amplitude is not obvious at the center and exciting points.

(3) There are obvious differences about the period of vibration from the results of transient response with/ without the restraining moments. It is observed that the period of vibration with restraining moments is shorter than that without the restraining moments, which means that ignoring the restraining moment will underestimate the stiffness of the structure system. So it is essential to take into account the effect of rotation stiffness provided by flexible pad in nonlinear transient analysis.

\section{Competing Interests}

The authors declare that they have no competing interests.

\section{Acknowledgments}

The authors gratefully acknowledge the financial support to this research work from National Natural Science Foundation of China (11502007, 11472020). 


\section{References}

[1] H. Kurtaran, "Geometrically nonlinear transient analysis of thick deep composite curved beams with generalized differential quadrature method," Composite Structures, vol. 128, pp. 241250, 2015.

[2] H. Kurtaran, "Geometrically nonlinear transient analysis of moderately thick laminated composite shallow shells with generalized differential quadrature method," Composite Structures, vol. 125, pp. 605-614, 2015.

[3] H. Kurtaran, "Large displacement static and transient analysis of functionally graded deep curved beams with generalized differential quadrature method," Composite Structures, vol. 131, pp. 821-831, 2015.

[4] S. Susler, H. S. Turkmen, and Z. Kazanci, "The nonlinear dynamic behaviour of tapered laminated plates subjected to blast loading," Shock and Vibration, vol. 19, no. 6, pp. 1235-1255, 2012.

[5] A. Naghsh and M. Azhari, "Non-linear free vibration analysis of point supported laminated composite skew plates," International Journal of Non-Linear Mechanics, vol. 76, pp. 64-76, 2015.

[6] P. Malekzadeh, "Differential quadrature large amplitude free vibration analysis of laminated skew plates based on FSDT," Composite Structures, vol. 83, no. 2, pp. 189-200, 2008.

[7] A. Alibeigloo and M. Shakeri, "Elasticity solution for the free vibration analysis of laminated cylindrical panels using the differential quadrature method," Composite Structures, vol. 81, no. 1, pp. 105-113, 2007.

[8] N. Nanda and J. N. Bandyopadhyay, "Geometrically nonlinear transient analysis of laminated composite shells using the finite element method," Journal of Sound and Vibration, vol. 325, no. 1-2, pp. 174-185, 2009.

[9] M. Amabili, "Theory and experiments for large-amplitude vibrations of rectangular plates with geometric imperfections," Journal of Sound and Vibration, vol. 291, no. 3-5, pp. 539-565, 2006.

[10] M. Amabili, "Nonlinear vibrations of rectangular plates with different boundary conditions: theory and experiments," Computers \& Structures, vol. 82, no. 31-32, pp. 2587-2605, 2004.

[11] P. Phung-Van, L. B. Nguyen, L. V. Tran et al., "An efficient computational approach for control of nonlinear transient responses of smart piezoelectric composite plates," International Journal of Non-Linear Mechanics, vol. 76, pp. 190-202, 2015.

[12] J. Chen, D. J. Dawe, and S. Wang, "Nonlinear transient analysis of rectangular composite laminated plates," Composite Structures, vol. 49, no. 2, pp. 129-139, 2000.

[13] A. Arbind and J. N. Reddy, "Transient analysis of Cosserat rod with inextensibility and unshearability constraints using the least-squares finite element model," International Journal of Non-Linear Mechanics, vol. 79, pp. 38-47, 2016.

[14] H. Li, L. Ying, and W. Sun, "Analysis of nonlinear vibration of hard coating thin plate by finite element iteration method," Shock and Vibration, vol. 2014, Article ID 941709, 12 pages, 2014.

[15] M. Amabili and S. Farhadi, "Shear deformable versus classical theories for nonlinear vibrations of rectangular isotropic and laminated composite plates," Journal of Sound and Vibration, vol. 320, no. 3, pp. 649-667, 2009.

[16] A. Fallah and M. M. Aghdam, "Thermo-mechanical buckling and nonlinear free vibration analysis of functionally graded beams on nonlinear elastic foundation," Composites Part B: Engineering, vol. 43, no. 3, pp. 1523-1530, 2012.
[17] H. Asadi and M. M. Aghdam, "Large amplitude vibration and post-buckling analysis of variable cross-section composite beams on nonlinear elastic foundation," International Journal of Mechanical Sciences, vol. 79, pp. 47-55, 2014.

[18] A. S. Kanani, H. Niknam, A. R. Ohadi, and M. M. Aghdam, "Effect of nonlinear elastic foundation on large amplitude free and forced vibration of functionally graded beam," Composite Structures, vol. 115, no. 1, pp. 60-68, 2014.

[19] P. Castro Jorge, F. M. F. Simões, and A. Pinto Da Costa, "Dynamics of beams on non-uniform nonlinear foundations subjected to moving loads," Computers \& Structures, vol. 148, pp. 26-34, 2015.

[20] A. Mamandi and M. H. Kargarnovin, "Nonlinear dynamic analysis of a timoshenko beam resting on a viscoelastic foundation and traveled by a moving mass," Shock and Vibration, vol. 2014, Article ID 242090, 10 pages, 2014.

[21] H. M. Sedighi, K. H. Shirazi, A. Reza, and J. Zare, "Accurate modeling of preload discontinuity in the analytical approach of the nonlinear free vibration of beams," Proceedings of the Institution of Mechanical Engineers, Part C: Journal of Mechanical Engineering Science, vol. 226, no. 10, pp. 2474-2484, 2012.

[22] H. M. Sedighi and K. H. Shirazi, "A new approach to analytical solution of cantilever beam vibration with nonlinear boundary condition," Journal of Computational and Nonlinear Dynamics, vol. 7, no. 3, Article ID 034502, 4 pages, 2012.

[23] W. L. Li, "Vibration analysis of rectangular plates with general elastic boundary supports," Journal of Sound and Vibration, vol. 273, no. 3, pp. 619-635, 2004.

[24] W. L. Li, X. Zhang, J. Du, and Z. Liu, "An exact series solution for the transverse vibration of rectangular plates with general elastic boundary supports," Journal of Sound and Vibration, vol. 321, no. 1-2, pp. 254-269, 2009.

[25] X. Zhang and W. L. Li, "Vibrations of rectangular plates with arbitrary non-uniform elastic edge restraints," Journal of Sound and Vibration, vol. 326, no. 1-2, pp. 221-234, 2009.

[26] V. Stojanović, "Geometrically nonlinear vibrations of beams supported by a nonlinear elastic foundation with variable discontinuity," Communications in Nonlinear Science and Numerical Simulation, vol. 28, no. 1-3, pp. 66-80, 2015.

[27] T. Yamaguchi, H. Hozumi, Y. Hirano, K. Tobita, and Y. Kurosawa, "Nonlinear transient response analysis for double walls with a porous material supported by nonlinear springs using FEM and MSKE method," Mechanical Systems and Signal Processing, vol. 42, no. 1-2, pp. 115-128, 2014.

[28] N. D. Duc, H. Hadavinia, P. V. Thu, and T. Q. Quan, "Vibration and nonlinear dynamic response of imperfect three-phase polymer nanocomposite panel resting on elastic foundations under hydrodynamic loads," Composite Structures, vol. 131, pp. 229-237, 2015.

[29] A. Shooshtari and S. Razavi, "Linear and nonlinear free vibration of a multilayered magneto-electro-elastic doubly-curved shell on elastic foundation," Composites Part B: Engineering, vol. 78, pp. 95-108, 2015.

[30] S. A. Eftekhari and A. A. Jafari, "Accurate variational approach for free vibration of variable thickness thin and thick plates with edges elastically restrained against translation and rotation," International Journal of Mechanical Sciences, vol. 68, pp. 35-46, 2013.

[31] M. V. Quintana and L. G. Nallim, "A general Ritz formulation for the free vibration analysis of thick trapezoidal and triangular laminated plates resting on elastic supports," International Journal of Mechanical Sciences, vol. 69, pp. 1-9, 2013. 
[32] D. J. Gorman, "Free vibration analysis of Mindlin plates with uniform elastic edge support by the superposition method," Journal of Sound and Vibration, vol. 207, pp. 335-350, 1997.

[33] A. K. Sharma, N. D. Mittal, and A. Sharma, "Free vibration analysis of moderately thick antisymmetric cross-ply laminated rectangular plates with elastic edge constraints," International Journal of Mechanical Sciences, vol. 53, no. 9, pp. 688-695, 2011.

[34] MSC/Nastran 2014 Dynamic Analysis User's Guide, MSC Software, 2014

[35] E. Sanmiguel-Rojas, M. Hidalgo-Martínez, J. I. JiménezGonzález, and A. Martín-Alcántara, "Analytical approaches to oscillators with nonlinear springs in parallel and series connections," Mechanism and Machine Theory, vol. 93, pp. 3952, 2015.

[36] W. P. Sun and B. S. Wu, "Large amplitude free vibrations of a mass grounded by linear and nonlinear springs in series," Journal of Sound and Vibration, vol. 314, no. 3-5, pp. 474-480, 2008.

[37] C. R. Lee and T. Y. Kam, "Identification of mechanical properties of elastically restrained laminated composite plates using vibration data," Journal of Sound and Vibration, vol. 295, no. 3-5, pp. 999-1016, 2006.

[38] S. H. Lee, MSC/Nastran Nonlinear Analysis Handbook Volume I Version 67, The Mac Neal-Schwendler Corporation, 1992.

[39] MSC, Nastran Version 70 Advanced Dynamic Analysis User's Guide, MSC. Software Corporation, 2009.

[40] MSC Nastran, 2014 Nonliners User's Guide SOL 400, MSC Software Corporation, Santa Ana, Calif, USA, 2014. 


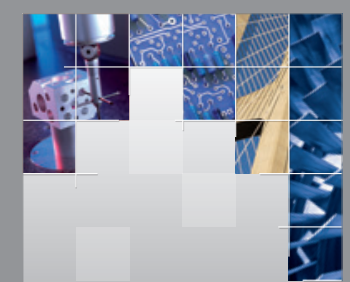

\section{Enfincering}
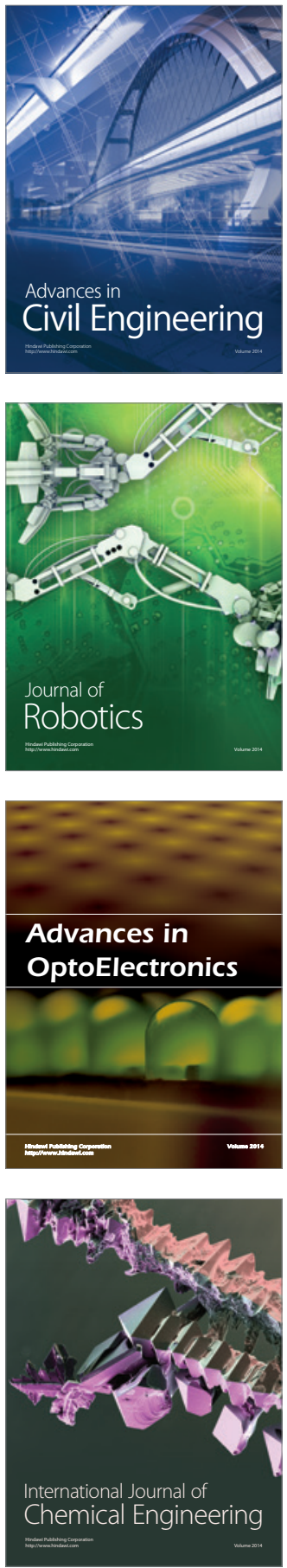

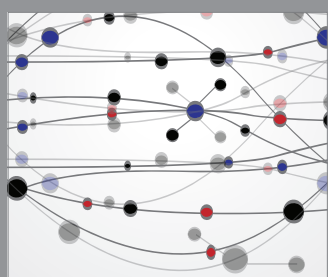

The Scientific World Journal

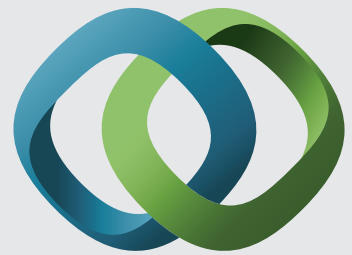

\section{Hindawi}

Submit your manuscripts at

https://www.hindawi.com
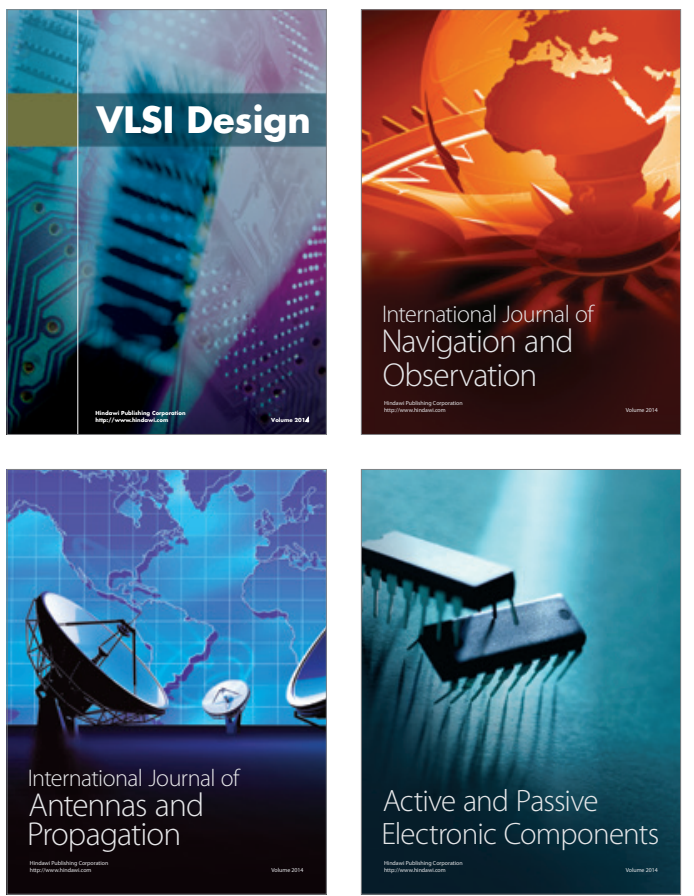
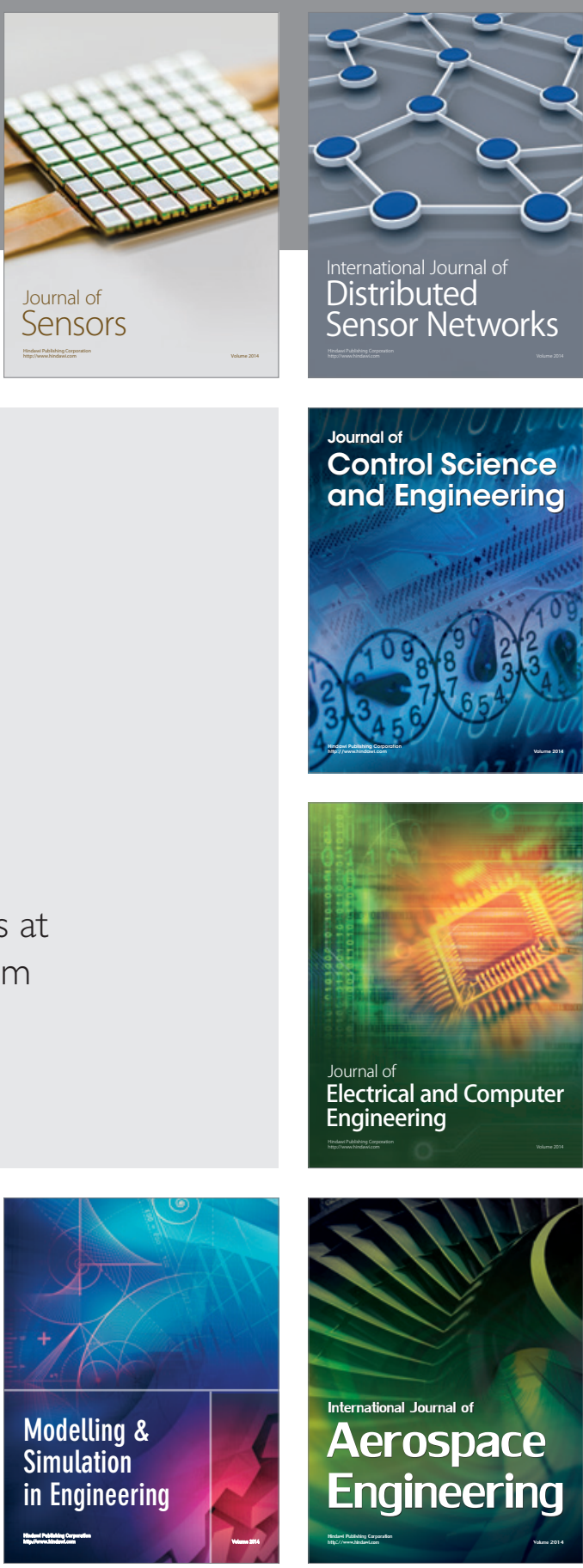

International Journal of

Distributed

Sensor Networks

$-$

Joumal of

Control Science

and Engineering
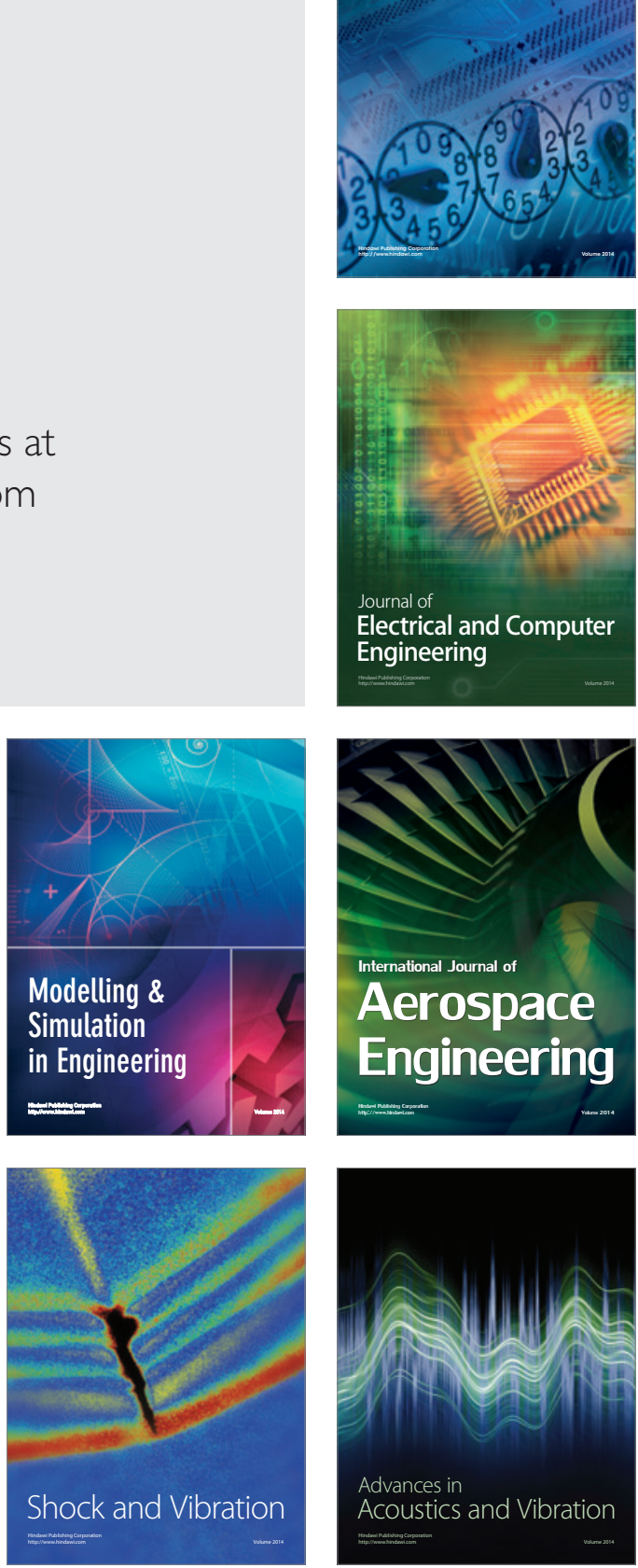